\title{
El desarrollo de la personalidad económica
}

\section{Development of economic personality}

\section{Entwicklung der wirtschaftlichen persönlichkeit}

\author{
Germán Rubio Guerrero', Fernando Adolfo Fierro Celis ${ }^{2}$
}

\section{Resumen}

El artículo destaca los diferentes aspectos de la sociedad económica, que influyen en el desarrollo del yo interior del individuo en su proceso de compra. Las variables económicas, las empresas y los límites morales del mercado condicionan al individuo a comportarse de determinadas maneras, que no necesariamente consultan sus verdaderas necesidades y que se constituye en un proceso meramente mercantilista como parte de una sociedad de consumo muchas veces superfluo.

Palabras claves: sociedad económica, límites morales, individuo, mercado, empresas.

\begin{abstract}
This article highlights the different aspects of the economic society that influence the individual's development in your shopping process. The economic variables, enterprises and the moral limits of the market, condition the individual to behave in certain ways, not necessarily view their real needs and becomes a purely mercantilist process as part of a consumer society often superfluous.
\end{abstract}

Keywords: economic society, moral limits, individual, market, enterprises.

\section{Zusammenfassung}

Der Artikel beleuchtet die verschiedenen Aspekte der Wirtschaftsgesellschaft, die die Entwicklung des Persons in seinem Prozess beeinflussen kann. Ökonomischen Variablen, Wirtschaft und moralischen Grenzen des Marktes konditionieren das Individuum auf eine bestimmte Weise zu kaufen, diese Variablen sind nicht ihre wirklichen Bedürfnisse und werden zu einem rein merkantilistischen Prozess als Teil einer Konsumgesellschaft oft überflüssig verhalten.

\section{Introducción}

El nuevo crecimiento individual dentro del mundo globalizado (Friedman, 2004), en donde el proceso de desarrollo de este se conoce y se presenta de diferentes maneras de acuerdo a las posibilidades económicas (Sen, 2000), que el contexto le brinde a las personas, hace que la identificación individual (Bauman, 2005), sea completamente diferente a los demás, pero estandarizado con la finalidad de las empresas. El fin es que los individuos dentro de una sociedad desarrollen una única forma de pensar, que emerja dentro de los conductismos de las organizaciones (Robbins, 2004) y que direccione los procesos de compra (camuflados por el bienestar). Desde esta perspectiva se pretende demostrar que el desarrollo del yo interior económico es posible a través de los bombardeos empresariales y sociales.
El desarrollo de este estado de cosas se enmarcará dentro de una de las teorías del desarrollo de la personalidad, propuesta por el filósofo y sicólogo Jean Piaget (1896-1980), en su discurso acerca de cómo los individuos poseen tres factores que establecen su identidad para determinar sus acciones y su comportamiento en un proceso de decisión (Chapman, 1988).

Como lo plantea Piaget, el ser humano es una balanza que se compone de tres partes, la primera hace referencia al yo, en donde están todas las variables familiares de la socialización primaria que moldean su personalidad (Leboyer, 1996), la segunda parte es el ello, que está influenciado por la parte externa de la familia del individuo conocida como socialización

1 - Docente de tiempo completo de la Universidad del Tolima. Administrador de Empresas. Especialista en Gerencia de Producción. Especialista en Estadística. Magister en Administración. Estudiante Doctorado en Gestión de la Universidad EAN.

2 - Docente de tiempo completo de la Universidad Surcolombiana. Administrador de Empresas. Especialista en Finanzas. Especialista en Gerencia en Servicio de la Salud y Seguridad Social. Magister en Administración. Master en Dirección de Recurso Humano. Estudiante Doctorado en Gestión de la Universidad EAN. 
secundaria y por último se encuentra el súper yo, que hace referencia al pensamiento del individuo dentro del análisis de su personalidad (Beilin, 1992), todo esto bajo la interiorización de los tres mundos (Popper, 1972)

Dentro de este contexto se presentan las siguientes analogías que se pretenden desarrollar, la primera es el valor de la sociedad (Patel, 2012), entendido como el yo, en el segundo punto están los límites de la moralidad (Sandel, 2013), entendido como el ello y por último se encuentra el individuo entendido como el súper yo (Bauman, 2005).

\section{Figura No. 1}

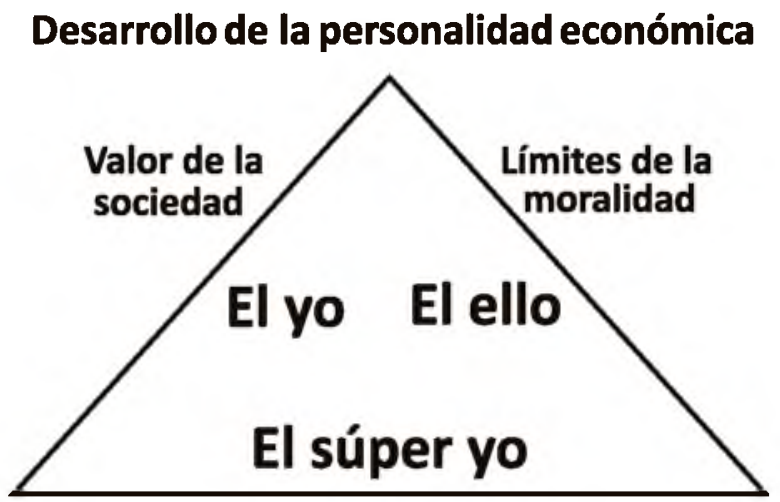

Modernidad liquida

Fuente: Propia con base en Patel (2012), Sandel (2013), Bauman 2005

\section{El Valor de la Sociedad (el yo)}

El yo, como socialización primaria se enmarca dentro del valor de la sociedad, es decir, qué valores o mensajes codificados está enviando la sociedad a la misma sociedad (conformada por individuos), en el momento de realizar transacciones económicas y que estas estén revestidas de formación social (McClelland, 1961).

Esta explicación, la presenta el consenso, como factor "para producir en la población mediante las nuevas técnicas de mercadeo (Kotler \& Keller , 2006), la aceptación de algo inicialmente no deseado", en donde esa nueva aceptación es impuesta de manera pacífica, sin realmente poder realizar un análisis crítico de lo que realmente es bueno para la sociedad y para el individuo dentro de ella.

Esto se presenta según (Chomsky \& Ramonet, 2010), porque "los intereses comunes esquivan totalmente a la opinión pública y solo una clase especializada de hombres responsables lo bastante inteligentes puede comprenderlos y resolver los problemas que de ellos se derivan" (p. 10) o sencillamente damos el poder a las personas que se autoproclaman CEO (Garten, 2001), para que tomen las decisiones por los demás o por el resto de la sociedad, lo que deja de lado el proceso democrático en una clase de personas (Acemoglu \& Robinson, 2012).

Este proceso democrático (Chomsky \& Ramonet, 2010), "es un sistema en el que la clase especializada esta entrenada para trabajar al servicio de los amos, de los dueños de la sociedad, mientras que al resto de la población se le priva de toda forma de organización para evitar así los problemas que pudiera causar" ( $p$. 19). Esto hace que los mensajes dirigidos a las diferentes comunidades no tengan detractor alguno, sino, más bien que sea aceptado e interiorizado, para que más adelante esta misma sociedad, se encargue de solicitar más mensajes codificados que les haga más fácil su vivir, sin posibilidades de negociar (Camp, 2004).

Esta codificación hace según (Chomsky \& Ramonet, 2010), que la "población esté profundamente adoctrinada para que no haya reparo en que no se está dando cancha a las opiniones de la oposición" (p. 40), modificando realidades, es decir, "el cuadro del mundo que se presenta a la gente no tiene la más mínima relación con la realidad y crea sus propios esquemas mentales (Senge, 2005), ya que la verdad sobre cada asunto queda enterrada bajo montañas de mentiras, que hacen que las personas sean más piadosas y no pongan en duda decisión alguna por parte de los directores de la sociedad, que presentan un panorama de acuerdo a lo que la sociedad desea ver y lo que la necesidad del individuo desea comprar.

Esto presenta un panorama de desigualdad en los hilos como en la historia conductora de la sociedad misma, es decir, qué sociedad se puede construir si está permeada por el deseo de una sola élite, además de construirse bajo cimientos falsos y el impacto que estos tienen sobre el desarrollo de la persona en su "yo interior" para la construcción de valores y de esta manera obtener un buen equilibrio en los procesos económicos.

Este discernimiento del bien y el mal (entre los valores que nos muestra la sociedad como los óptimos, y, los valores adecuados para la sociedad escogidos por el individuo), hace que exista una línea difusa entre los valores que aporta la sociedad y cuáles de ellos la persona absorbe como valores ciertos para ella.

En este sentido Patel (2012), plantea que "la idea de que todo puede ser etiquetado con un precio, no solo agrada muchísimo a nuestros políticos y a nuestras elites empresariales, sino que también puede llevar a la tragedia social" (p. 27). Esta situación se refleja en los límites morales de mercado y el mensaje a los individuos como compradores acerca de que todo tiene un precio, lo importante es colocárselo.

Estos nuevos precios según Patel (2012), hacen que:

Vivamos atrapados en una cultura que insiste en que la forma más adecuada de ver el mundo es a 
través de un mercado salvaje, al declarar que mediante el ejercicio ilimitado de la oferta y la demanda, podemos hacer del mundo un lugar mejor (Patel, 2012, p. 33).

Pero bajo qué costo moral se puede presentar ese mejoramiento de la vida humana si se ha construido bajo valores superfluos. Los valores infundidos por la sociedad según Patel (2012) hacen que:

Cada uno se vuelva producto de su propia felicidad. En sus mismos términos, obtenemos nuestra propia utilidad al combinar de manera productiva los bienes y servicios adquiridos en el mercado con nuestro propio tiempo en el hogar. En otras palabras, la felicidad es el resultado de sumar las cosas que compramos y el tiempo que empleamos en usarlas (Patel, 2012, p. 49).

Lo que desemboca en la infelicidad de los individuos por la falta de recursos económicos para la obtención de los productos, permeando valores morales, que se ven reflejados en lo que se compra.

Por otro lado, el reforzamiento de los valores del "yo", están influenciados por valores, planeación y gestión empresarial (Amaya, 2005). Esto se presenta por que todos hacen parte de una empresa y un gran lapso de tiempo de vida se queda en la organización, y a través de este periodo se adquieren valores que influyen de manera directa o indirecta en la sociedad y en los individuos. Este comportamiento empresarial según Mintzberg \& Quinn (1988), propuesto en su ápice estratégico se identifica con lo argumentado por Patel (2012), cuando expone:

Rompen la ley siempre que sea posible, disimulan y ocultan sus acciones, sacrifican el bienestar a largo plazo por la ganancia inmediata, son agresivas y contenciosas, hacen caso omiso de las normas de salud y de seguridad, huyen del pago a sus proveedores y empleados, y nunca jamás sienten una grano de culpa (Patel, 2012, p. 60).

Esta situación es irradiada de la misma manera a los trabajadores que influyen dentro de la primera célula social, es decir, se adquieren valores en la empresa y se trasmiten a la familia para la construcción del propio "yo" interior y el "yo" interior de los integrantes de la familia.

Estas nuevas estructuras empresariales (Chandler, 1962), hacen que los mercados estén dirigidos solo por la obtención de ganancia percibida a través de los indicadores financieros (Ortiz, 2011), situación que distorsiona el fin del mercado y deja a las empresas (Patel, 2012), libres de "decidir que producir y a qué precio vender, actuando como seres fríos y calculadores, motivados nada más que por su propio beneficio, en un mundo donde los factores productivos pueden comprarse y venderse de manera libre en el mercado" (p. 61), lo que permite moldear los valores de acuerdo a las tendencias del mercado dejándolos al libre albedrío, sin anclaje moral social, solo anclaje moral empresarial, acorde a su planeación (Fernández, 2006).

Este escenario permite que los valores morales evolucionen según el poder relativo de los actores sociales, que emergen en las diferentes comunidades dependiendo de su situación geográfica, lo que desemboca en que cada sociedad tenga su propio conjunto de normas y costumbres (Yunis, 2009), que son longevas y hereditarias acordes a las relaciones de poder de aquellos que controlan los recursos al asignar valores y cambiar la pirámide de las necesidades (Maslow, 1954).

Lo importante de este desarrollo, el "yo", es que está permeado y se desarrolla de manera amorfa de acuerdo a los mensajes sociales, en la semiótica empresarial y de educación (Schvarstein, 1992), que se emiten desde una forma de ver el mundo creando fenomenología empresarial mas no social (Husserl, 1987), situación que se puede realizar sin ponerle precio a los productos o de lo contario la sociedad se enfrentaría a diferentes desarrollos del "yo", que se verán influenciados por valores de moda, es decir se toman las decisiones de acuerdo al valor que esté de moda o impuesto por la sociedad.

\section{Figura No. 2}

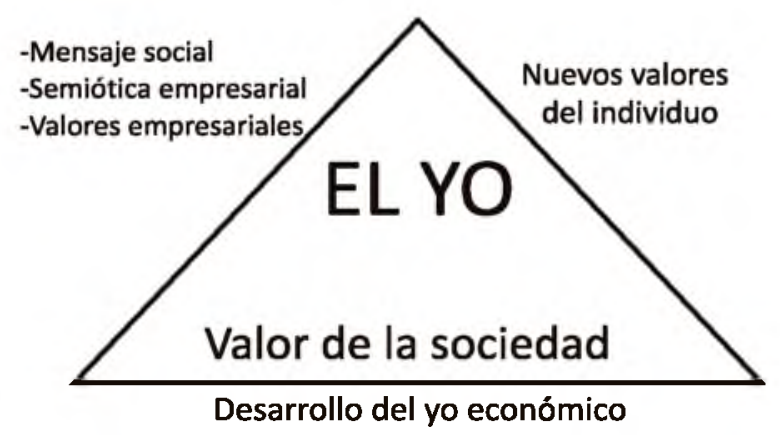

Fuente: Propia con base en Patel (2012), Sandel (2013), Bauman 2005

\section{Los Límites de la Moralidad (Ello)}

Para establecer el "ello", el principal proveedor de materia prima para la edificación de la personalidad económica son los mercados y su competitividad (Porter, 1991), los cuales según Sandel (2013), "a lo largo de las últimas tres décadas, los mercados y los mercados de valores, han llegado a gobernar nuestras vidas como nunca antes lo habían hecho" (p. 13), transformando en criterio de Sandel (2013), "la lógica del comprar y vender no solo a los bienes materiales, sino que gobierna cada vez más otros aspectos de la vida" (p. 14), que fortalecen la personalidad del individuo como comprador, al crear una nueva fenomenología de la interacción entre el individuo y el mercado (Herrera, 1998). 
A su vez, la falta de moral en el corazón del triunfalismo del mercado se debe a la codicia, la cual incita a asumir riesgos de manera irresponsable (Sandel, 2013), y "hacen que la intromisión de los mercados y del pensamiento orientado a los mercados, en aspectos de la vida tradicionalmente regidos por las normas no mercantiles es uno de los hechos más significativos de nuestro tiempo" (p. 15), esto se presenta por la innovación disruptiva (Schumpeter, 1939), y la ansiedad de los compradores en obtener el último artículo del mercado a cualquier costo.

Este nuevo despertar hace que el "ello" pretenda (Sandel, 2013):

Una tendencia corrosiva natural de los mercados (Stiglitz, Caída Libre, 2010), al poner un precio a las cosas buenas de la vida para corromperlas. Porque los mercados no solo distribuyen bienes, sino que también expresan y promueven ciertas actitudes respecto a las cosas que se intercambian (Sandel, 2013, p. 17).

Desde esta perspectiva se imponen nuevos valores y métodos de colocar precio a las cosas que se desean. Esta nueva imposición de precios permea de manera rápida la forma de valorar lo productos y necesidades, brindando nuevos marcos tanto en la personalidad como en la toma de decisiones en el momento de efectuar valoraciones desde y hacia el mercado (Kahneman \& Tversky, 1974). Esto se evidencia en la transición de una economía de mercado eficaz para organizar la actividad productiva (Taylor, 1971), hacia una economía de sociedad, que se refiere según Sandel (2013), a "una manera de vivir en la que los valores mercantiles penetran en cada aspecto de las actividades humanas. Es un lugar en donde las relaciones humanas están hechas a imagen del mercado" (p. 18). Lo que corrobora el soporte de la tesis de este artículo, especialmente en donde los límites del mercado ayudan a la definición de personalidad económica ("el ello"), trasformando su inteligencia emocional (Goleman, 1996).

Este aspecto crea y camufla una nueva versión de ética y corrupción, que en términos de Sandel (2013)

Se asocia la corrupción al dinero obtenido de forma ilícita. Pero el concepto de corrupción abarca mucho más que los sobornos y los pagos ilícitos. Corromper un bien o una práctica social significa degradarlos, darles un valor inferior al que le corresponde (Sandel, 2013, p. 42).

Este hecho de manera inconsciente acepta de forma exacta, algo inexacto, que profundiza nuestro ser y la forma de ver las realidades, cambiando las normas, sin estar claro que principio debe prevalecer.

Bajo estos principios no se muestra de manera clara según Sandel (2013), "bajo qué condiciones las relaciones comerciales reflejan libertad de elección y bajo qué condiciones ejercen algún tipo de coacción" (p.51), enfocados hacia la sociedad, que percibe el valor social que se pretende formar e implementar.

Para este proceso es importante comprender que las "relaciones mercantiles son apropiadas en ciertos dominios y se ha de entender qué normas deben regir el proceder" (Sandel, 2013, p. 53), porque "lo que comienza siendo un mecanismo de mercado se convierte en una norma de mercado. La preocupación obvia es que el pago" (Sandel, 2013, p. 66) a los individuos puede acostumbrarlos a ver en el mercado una manera de hacer dinero, minando así, o desplazando o corrompiendo el amor o el valor mercantil de la sociedad, con lo cual se fortalece la relación mercantilista entre el comprador y el mercado.

Estas, relaciones humanas (McGregor, 1960), son en última instancia (Sandel, 2013), relaciones mercantiles, que dejan su impronta en las normas sociales que simplemente los mercados reflejan y fomentan ciertas formas consideradas normales de valorar los bienes que se intercambian, inclusive los morales desplazando normas no mercantiles que "conforme los mercados y el pensamiento orientado al mercado van invadiendo esferas de la vida tradicionalmente regidas por normas no mercantiles", en cuyo caso "los mercados no puede dilucidarse a partir de cuestiones controvertidas sobre la manera justa de valorar los bienes que se intercambian" (p 82-86).

Esto puede verse sencillamente como un grupo de personas que interactúan (Mayo, 1949), unas con otras cuando hacen sus vidas, pero sin embargo hay que tener en cuenta la interacción humana en general y los principios de acuerdo con los cuales los individuos toman decisiones que enmarcan su proceso de compra, que según Sandel (2013), hace la:

Distinción entre teoría económica y ética, entre razonamiento mercantil y razonamiento moral, la moralidad representa el modo como nos gustaría que el mundo se comportara, y la ciencia económica representa el modo como realmente se comporta, la economía es una ciencia que no hace valoraciones, que es independiente de toda filosofía moral y política de la sociedad en general. Lo cual siempre ha sido cuestionable (Sandel, 2013, p. 93).

Al mismo tiempo, tienen que prever (Sandel, 2013):

Si poner precio a una actividad desplazará las normas no mercantiles. Y para prever esto tienen que investigar los supuestos morales que configuran una práctica dada y determinar si la mercantilización de esa práctica (aplicándole un incentivo o una medida disuasoria de orden económico) desplazará esos supuestos (Sandel, 2013, p. 95).

Apoyados en Sandel (2013), "la sicología moral (que normas existen y como los mercados pueden afectarlas) y en la filosofía moral (cuando los mercados 
erosionan las normas no mercantiles) (p. 95), de esta manera "el razonamiento mercantil introduce de contrabando ciertos juicios morales a esa pretensión de ser neutral en cuestión de valores" (p. 107), que son la base fundamental para el proceso del crecimiento del individuo y sus posibles efectos ante la sociedad y la globalización (Stiglitz, 2010).

Esta nueva forma de mercado con sus intraemprendedores (Garzón, 2005), hace que se analice la posibilidad que "los mercados no son meros mecanismos de intercambio; encarnan ciertos valores, y a veces, los valores del mercado desplazan normas no mercantiles que merecen ser preservadas" (Sandel, 2013), con el fin de que exista eficiencia en el intercambio mercantil y que las dos partes salgan beneficiadas sin perjudicar a otros, al suponer que las relaciones mercantiles y las actitudes que fomentan no disminuyen el valor de los bienes que se intercambian, sin embargo, esto se ve de manera parcial, debido a que "conforme los mercados se extienden a esferas de la vida tradicionalmente regidas por normas no mercantiles, la idea de que los mercados no tocan o contaminan los bienes que en ellos se intercambian se tornan cada vez menos plausibles", al no percibir los cambios inducidos en el mercado, para beneficios de las grandes corporaciones (p. 116-118).

Se puede determinar que en ocasiones los valores morales del mercado hacen que en todos los aspectos, se pueda perpetuar un cierto comportamiento (Spencer \& Spencer, 1993) y se reproduzca dentro de la sociedad, impidiendo el fortalecimiento del "ello" dentro de la socialización secundaria influenciada por los límites morales del mercado, al fortalecer las competencias laborales (Mertens, 1997).

Esta nueva socialización secundaria se puede destruir más al ingresar el factor económico dentro de la institucionalidad del individuo (Sandel, 2013), "la introducción del dinero en dominios no mercantiles puede cambiar las actitudes de las personas y desplazar compromisos morales y cívicos" que al "considerar las normas morales y cívicas simplemente como formas rentables de motivar a las personas" "pueden cambiar las actitudes de las personas y desplazar valores no mercantiles" (Lucia \& Lepsinger, 1999 , p. 122-123) al modificar nuevamente el fortalecimiento del desarrollo de la personalidad económica.

Al tener esta malformación del mercado regida por los valores de la elite y fortalecido por los valores del mercado a través del intercambio comercial y la creación de nuevos mercados (Chan \& Mauborgne, 2005), se ve claramente como alteran el carácter de los bienes que tocan, es importante preguntar según Sandel (2013), "cuál es, y, cual no es el sitio de los mercados. Y no se puede responder a esta pregunta sin reflexionar sobre el significado y la finalidad de los bienes y sobre los valores que deberán gobernarlos" (p. 206).
Para este fin afirma Sandel (2013), que la "única esperanza de mantener a los mercados en su sitio es reflexionar de forma abierta y publica sobre el significado de los bienes y las prácticas sociales que se valoran" (p. 207) y orientar los esfuerzos por el tipo de sociedad que se desea construir. No es fácil enseñar a las personas "a ser ciudadanos capaces de pensar de forma crítica acerca del mundo que los rodea, cuando buena parte de la infancia la ocupa la capacitación básica para vivir en una sociedad de consumidores" (Sandel, 2013, p. 205).

Sin embargo, existe la esperanza que todos estos valores que se permean (Sandel, 2013), como lo son:

El altruismo, la generosidad, la solidaridad y el civismo no son como mercancías que disminuyen con el uso. Son como músculos que se desarrollan y fortalecen con el ejercicio. Uno de los defectos de una sociedad dirigida por el mercado es que hace que estas virtudes languidezcan. Para renovar nuestra vida pública necesitamos practicarlas con más energía (Sandel, 2013, p. 205).

Valores estos que se han perdido o trasformado en el tiempo de acuerdo a las necesidades de la sociedad. Tal y como lo plantea Aristóteles citado por (Sandel, 2013), al señalar que la virtud es algo que cultivamos con la práctica: nos volvemos justo con los actos justos, mesurados con los actos mesurados, valerosos con los actos valerosos, sin embargo al plantearse este factor de crecimiento y según Aristóteles, cabe preguntarse cómo se pueden mejorar o renovar estos valores sociales, si ya están infectados por valores mercantiles que desplazan a los no mercantiles, y desarrollan el "ello" de la personalidad económica.

Figura No. 3

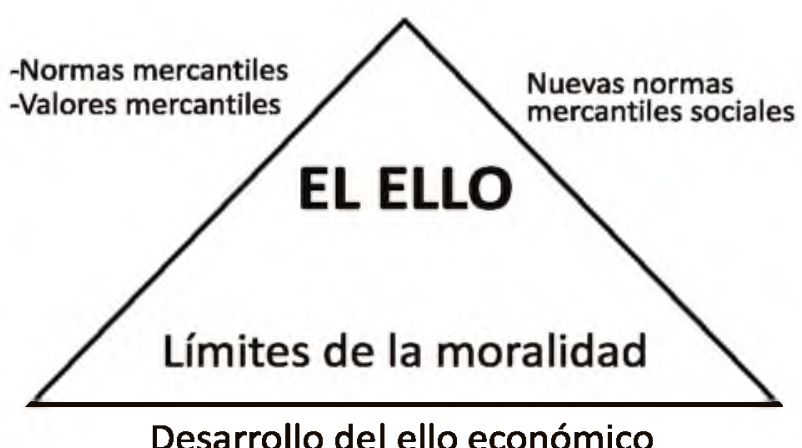

Fuente: Propia con base en Patel (2012), Sandel (2013), Bauman 2005

\section{El Individuo (El Súper Yo)}

El desarrollo de la personalidad económica, está fundamentado en la modernidad liquida de Zygmunt Bauman (2005), en donde explica de manera clara la influencia del individuo (como súper "yo" para este caso) en los procesos mercantiles. El principio del desarrollo del individuo como "súper yo", según 
Bauman (2005), ayuda a explicar el desarrollo del individuo bajo el siguiente planteamiento:

Lo que compartían era el presagio de un mundo estrechamente controlado, en el que la libertad individual no solo estaba hecha añicos sino que ofendía gravemente a la gente entrenada para obedecer órdenes y seguir rutinas prefijadas; un mundo en el que una pequeña elite tenía en sus manos todos los hilos -de modo que el resto de la humanidad eran meros títeres-; un mundo dividido en manipuladores y manipulados, planificadores y cumplidores de planes-los primeros ocultaban los planes y los segundos ni siquiera sentían deseos de espiarlos para comprender su sentido-, un mundo en el que cualquier otra alternativa resultaba inimaginable" (Bauman,2005, p.59)

Lo que permite predecir que las personas bajo el mando de la elite, están preparadas para ser controladas de manera natural, al permitir estructurar mentes (Boyatzis, 1982), que estén preparadas para recibir, mas no para percibir, lo que la sociedad "necesite" y no lo que realmente quiere.

Esta influencia establece nuevas formas de conducta y de adiestramiento empresarial (Ouchi, 1981), para el individuo como para la sociedad en donde, las nuevas formas de pensar como el fordismo (1954), y el taylorismo (1971), profundizan estas nuevas etapas, tal como se plantea en la siguiente apreciación de Bauman(2005):

El fordismo fue en sus días de gloria, un modelo de industrialización, de acumulación, de regulación (...) una combinación de formas de adaptación de las expectativas y la conducta contradictoria de los agentes individuales con respeto a los principios colectivos del régimen de acumulación (....). El paradigma industrial incluía el principio taylorista de racionalización que se basaba en la separación de los aspectos intelectuales y manual de trabajo (.....). El conocimiento social era sistematizado desde la cima y los planificadores lo incorporaban a las maquinarias (Bauman, 2005, p. 62).

Cuando Taylor y los ingenieros tayloristas introdujeron estos principios a comienzos del siglo $\mathrm{XX}$, su objetivo explícito era reforzar el control de los gerentes sobre los trabajadores (Alles, 2009), lo cual conlleva a un nuevo oleaje de orden, monotonía, regulación. (Bauman, 2005), afirma al respecto "un entorno en donde se considera que algunos acontecimientos tienen más posibilidades de ocurrir que sus contrarios y cuando otros acontecimientos no tienen casi posibilidad de producirse o son directamente descartados" (p. 61), bajo este esquema se puede ver claramente el proceso del desarrollo de la personalidad económica, en cuanto a establecer las bases de pensamiento de la toma de decisiones y los factores a tener en cuenta en el "supero yo" del individuo.
Estas nuevas posibilidades crean todo un "conteiner lleno hasta el borde de innumerables oportunidades que aún deben buscarse o que ya se han perdido. Hay más posibilidades -muchísimas más- de las que cualquier vida individual, por larga, industriosa $y$ osada que sea, podría explorar, y menos todavía adoptar" (Bauman, 2005, p. 67) para crear nuevos esquemas sociales que dependen del individuo.

Lo importante es que a este individuo según Bauman (2005), le "corresponda descubrir que es capaz de hacer y ampliar esa capacidad al máximo y elegir los fines a los cuales aplicar esa capacidad -o sea, aquellos que le produzcan la mayor satisfacción (Harford, 2007). Al individuo le corresponde domesticar lo inesperado para convertirlo en entrenamiento" (p. 68), de esta manera es más plausible el logro de construcción mental orientado al desarrollo de la sociedad.

Sin embargo el proceso de conversión y de construcción mental, significa que "nada ha terminado y que todo está por delante, el "ser alguien" que esa conversión promete augura el silbato final del árbitro: no eres más libre" (Bauman, 2005). Cuando has alcanzado tu propio mundo, no eres tú mismo cuando te has convertido en alguien" (p. 68), lo que implícitamente lleva a pensar que las personas "cuando no pueden errar, tampoco puede estar seguras de haber acertado. Si no hay actos equivocados, nada permite distinguir un acto acertado" (p.69), y por lo tanto es imposible reconocer cual es el acto correcto entre muchas alternativas, ni antes ni después de haber actuado, factor importante en la construcción del "súper yo" económico. De esta manera el error hace parte de la construcción, sin embargo, lo interesante es que se aprenda de ese error y cómo está enfocado a la construcción de sociedad e individuo.

Este proceso de construcción a través del aprendizaje del error se ve reflejado en las palabras de Margaret Thatcher citada en Bauman (2005):

"No existe la sociedad", significa que no hay utopía ni distopía; como lo expreso Peter Drucker (2002), el gurú del capitalismo light, "la sociedad ya no salva", sugiriendo (aunque más por omisión) que la responsabilidad de la condena tampoco corresponde a la sociedad: tanto la redención como la condenación son responsabilidades de cada uno, resultado de lo que cada uno, como agente libre hace su propia vida. Estas frases de estos pensadores (Thatcher como Drucker) soportan la tesis de como la modernidad liquida hace que se construya"

Y de esta manera exista una nueva realidad de vida del "súper yo", que al fin de cuentas se fortalece para la personalidad económica del individuo en una sociedad de compra.

En esta nueva sociedad de consumo según Bauman (2005), "comparten la dependencia del consumo -la dependencia universal de comprar- es la condición sine qua non de toda libertad individual; sobre todo, de 
la libertad de ser diferente, de tener identidad" con el propósito que "el carácter genuino de la libertad de lección del consumidor, especialmente su libertad de auto identificarse por medio del uso de productos masivos y comercializados, es un tema discutible. Esa libertad no existe sin las sustancias y los materiales abastecidos por el mercado" lo que permite que "en un mundo en el que las cosas deliberadamente inestables son la materia prima para la construcción de identidades necesariamente inestables, hay que estar en alerta constante; pero sobre todo hay que proteger la propia flexibilidad y la velocidad de readaptación para seguir las cambiantes pautas del mundo de "afuera" (p. 90-92).

Esta nueva "modernidad liquida, es una asociación de posibilidades indefinidas e infinitas, lo que lo ha tornado vacilante y frágil. Lo que ayer se consideraba normal y satisfactorio hoy puede resultar preocupante y hasta patológico y requerir una cura" (Bauman, 2005, p. 85), situación que pone en riesgo el fortalecimiento del "súper yo", debido a los aspectos y mensajes cambiantes de la sociedad ante el individuo y del individuo ante él mismo.

Para concluir este artículo, es importante citar a (Chomsky \& Ramonet, 2010), en los siguientes términos:

"Hay que hacer que conserven un miedo permanente, porque a menos que estén debidamente atemorizados por todos los posibles males que pueden destruirlos, desde adentro o desde afuera, podrán empezar a pensar por sí mismos, lo cual es muy peligroso ya que no tienen la capacidad de hacerlo. Por ello es importante distraerlos y marginarlos"

Esta distracción hace que las personas sean manejables para la clase del nuevo individuo consumidor que necesita la sociedad.

\section{Figura No. 4}

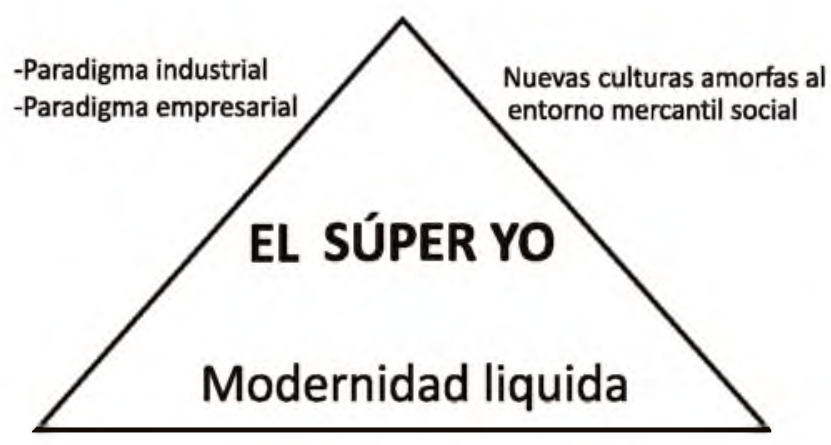

Desarrollo del súper yo económico

Fuente: Propia con base en Patel (2012), Sandel (2013), Bauman 2005

\section{Conclusiones}

Los límites del mercado son insaciables y cambiantes de acuerdo a las necesidades de la sociedad, bajo la sombra de la identidad propia de las organizaciones (Ader, 1993). En este sentido la moralidad del mercado permea de manera amorfa los valores del individuo como de la sociedad, lo que desencadena la estructuración de un nuevo ciudadano y su propia autopoiesis (Luhmann, 1997).

La nueva modernidad pone en riesgo, la consecución de los valores y la perpetuidad de los mismos, lo que hace que en cada generación de individuos, estos tengan poco o mucho impacto, de acuerdo a la situación y su racionalidad limitada (Simon, 1957). Desde esta perspectiva los mercados y la sociedad se construyen en conjunto, como un sistema (Bertalanffy, 1984), uno es complementario del otro, lo difícil es conocer cuáles son los límites de cada uno y hasta donde se reconoce el papel del otro, solo un circulo virtuoso para las empresas y circulo vicioso para la sociedad.

\section{Figura No. 5}

\section{NUEVA PERSONALIDAD ECONÓMICA}

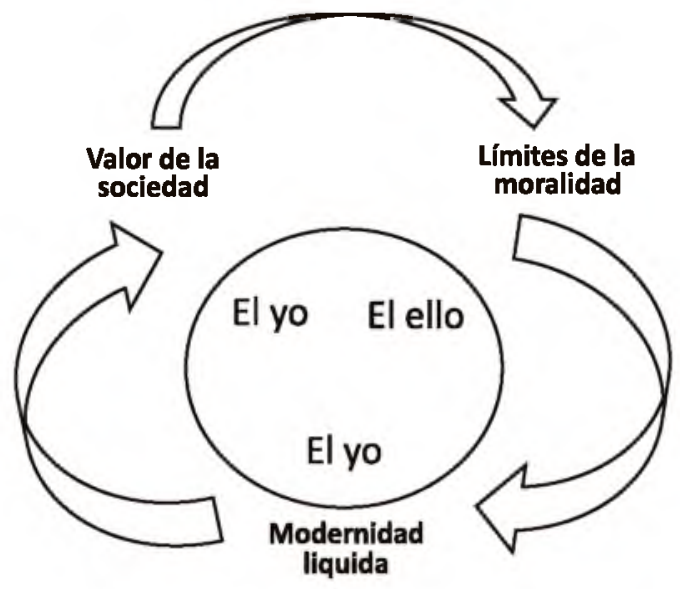

Fuente: Propia con base en Patel (2012), Sandel (2013), Bauman 2005

\section{Referencias Bibliográficas}

Acemoglu, D., \& Robinson, J. (2012). Por qué fracasan los países. Bogotá: Planeta.

Ader, J. (1993). Organizaciones. Buenos Aires: Editorial Paidós.

Alles, M. (2009 ). Dirección estratégica de recursos humanos: gestión por competencia. Buenos aires: Granica.

Amaya, J. (2005). Gerencia: Planeación \& estratégia. Bogotá: Universidad Santo Tomas de Aquino.

Bauman, Z. (2005). Modernidad liquida. Argentina: Fondo de cultura económica.

Beilin, H. (1992). La contribución permanente de piaget a la psicologia del desarrollo. London: Developmental Psycology.

Bertalanffy, L. (1984). Teoría General de los Sistemas: fundamentos, desarrollo, aplicaciones. México: Fondo de Cultura Económica. 
Boyatzis, R. \&. (1982). The competent manager: A model for effective performance. New york: Wiley.

Camp, J. (2004). De Entrada Diga No: Las Herramientas Que Los Negociadores No Quieren Que Usted Conozca. Bogotá: Empresa Activa.

Chan, W., \& Mauborgne, R. (2005). La estrategia del océano azul, cómo crear espacios no disputados en los que la competencia sea irrelevante. Barcelona: Ediciones Granica.

Chandler, A. (1962 ). Strategy and structure: Chapters in the history of the american industry enterprise. Washington D.C.: Beard Books.

Chapman, M. (1988). La evolución del constructivismos: origenes y desarrollo del pensamiento de piaget. Cambridge: Cambridge university.

Chomsky, N., \& Ramonet, I. (2010). Cómo nos venden la moto. Barcelona: Icaria.

Drucker, P. (2002). La gerencia en la sociedad futura. Bogotá: Norma.

Fernández, A. (2006). Fundamentos de la organización de empresas. Madrid: Narcea.

Ford, H. (1954). Mass production, modernism and design. Manchester: Manchester university press.

Friedman, t. (2004). La tierra es plana. Bogotá: Norma.

Garten, J. (2001). La Mentalidad del CEO. Bogotá: Norma.

Garzón, M. (2005). El Modelo Intraemprendedor Para la Innovación Bogotá D.C.: Colección Lecciones Centro Editorial Universidad del Rosario.

Goleman, D. (1996). Inteligencia emocional. Barcelona: Kaíros.

Harford, T. (2007). El economista camuflado. Madrid: Ediciones planeta.

Herrera, D. (1998). América Latina y la fenomenología. México: Universidad Pontifícia de México. Colección Investigación UPM, No 7.

Husserl, E. (1987). El espíritu común (Gemeingeist. Obra póstuma.

Kahneman, D., \& Tversky, A. (1974). Judgment Under Uncertainty: Heuristic and Biases. Sciences, New series, Vol 185., 1124-1131.

Kotler, P., \& Keller , K. (2006). Dirección de marketing. México: Pearson educación.

Leboyer, C. (1996). Gestión de las competencias. Como Analizarlas, Como Evaluarlas, Como Desarrollarlas. Paris: Les éditions d' organisation.

Lucia, D., \& Lepsinger, R. (1999). The art and science of competency models. San francisco: Jossey-Bass.

Luhmann, N. (1997). Organización y Decisión. Autopoiesis, acción y entendimiento. Barcelona: Anthropos Editorial.
Maslow, A. (1954). Motivation and personality. New York: Harper \& Row.

Mayo, E. (1949). The social problems of an industrial civilization. Abingdon: Routledge.

McClelland, D. (1961). La Sociedad Ambiciosa. Madrid: Ediciones Guadarrama.

McGregor, D. (1960). The human side of enterprise. New York: McGraw-Hill.

Mertens, L. (1997). Sistemas de competencia laboral surgimiento y método. Seminario internacional sobre formación basada en competencia laboral situación actual y perspectivas (págs. págs. 27-41). Montevideo: CINTERFOR.

Mintzberg, H., \& Quinn, J. (1988). El Proceso Estratégico. México: Editorial Prentice Hall.

Ortiz, H. (2011). Análisis financiero aplicado. Bogotá: Universidad externado de Colombia.

Ouchi, W. (1981). Theory Z: How american business can meet the japanese challenge. New York: Perseus book.

patel, R. (2012). Cuando nada vale nada.Bogota: Icono.

Popper, K. (1972). Objective Knowledge, an Evolutionary Approach. New York: Oxford University Press.

Porter, M. (1991). La ventaja competitiva de las naciones. Barcelona: Plaza y Janés.

Robbins, S. (2004). Comportamiento Organizacional. Mexico: Pearson Educación

Sandel, M. (2013). Lo que el dinero no puede comprar. Bogotá: Debate.

Schumpeter, J. (1939). Business Cicles: a Theoretical Historical and Stadistical Analysis of Capitalist Process. New York: McGraw Hill.

Schvarstein, L. (1992). Psicología de las Organizaciones: nuevos aportes. Buenos aires: Editorial Paidós.

Sen, A. (2000). Development as Freedom. New York: Afred A. Knopf.

Senge, P. (2005). El Arte y la Práctica de la Organización Abierta al Aprendizaje . Buenos Aires: Granica.

Simon, H. (1957) . A behavioral model of rational choice, in models of man, social and rational: mathematical essays on rational human behavior in a social setting. New York: Wiley.

Spencer, L., \& Spencer, S. (1993). Competence at Work, Models for a superior perfomance. Canada: Jhon Wiley \& Sons, Inc.

Stiglitz, J. (2010). Caída Libre. Bogotá: Editorial Taurus.

Stiglitz, J. (2010). Como hacer que funcione la globalización. Madrid: Santillana ediciones.

Taylor, F. (1971). Principios de la administración científica. México: Herrera Hermanos.

Yunis, E. (2009). ¿Por qué somos así?, análisis del mestizaje. Bogota: Temis. 